\title{
A randomised prospective study of treatment of non- ischaemic central retinal vein occlusion by isovolaemic haemodilution
}

\author{
L L HANSEN,' J WIEK,' AND M WIEDERHOLT ${ }^{2}$ \\ From the Departments of 'Ophthalmology and ${ }^{2}$ Clinical Physiology, Klinikum Steglitz, Freie Universität \\ Berlin, West Germany
}

SUMMARY In a randomised study 25 patients over 50 years of age with non-ischaemic central retinal vein occlusion (CRVO) were assigned to either a treatment (14 patients, isovolaemic haemodilution) or a control group (11 patients, no treatment). After three months eight eyes in patients with haemodilution improved, whereas none of the untreated eyes had better visual acuity $(p<0 \cdot 01)$. Thirteen haemodiluted and 11 control patients could be observed for one year. Six eyes of the haemodiluted patients retained a better visual acuity, whereas no improvements had occurred in the control group $(\mathrm{p}<0.025)$. In fluorescein angiography the lowering of the packed cell volume to $35-32 \%$ accelerated the time of maximal venous filling $\left(t_{m v f}\right)$ from $17 \cdot 4($ SEM 1.4$) s$ to $11.4($ SEM 0.9) s $(p<0.005)$. In patients with non-ischaemic CRVO without treatment the passage time did not change. The shortened $t_{m v f}$ reflects a higher blood velocity. Thus isovolaemic haemodilution improves the visual prognosis in non-ischaemic CRVO probably by inducing a higher blood fluidity, which results in higher blood velocity, at least in areas of compromised retinal microcirculation.

Since von Michel' categorised the entity of central retinal vein occlusion (CRVO) more than 100 years ago numerous experimental and clinical studies on this disease have been carried out. However, CRVO continues to lead to visual disability in most cases, especially in patients suffering from the ischaemic type, ' though the most serious complication, namely, ocular neovascularisation of various types, can be prevented by panretinal photocoagulation..$^{-.5}$

In a randomised prospective study ${ }^{6}$ we showed that the visual outcome of patients with CRVO can be improved by isovolaemic haemodilution (IHD). This kind of treatment had been prompted by finding increased whole blood and plasma viscosity in patients with CRVO. ${ }^{7-9}$

But, as our first study ${ }^{6}$ indicated that ischaemic CRVO might respond better to IHD than its nonischaemic counterpart, we also performed this randomised trial to find out whether IHD improves the visual outcome in patients with nonischaemic CRVO in comparison with untreated patients.

\section{Patients and methods}

Venous obstructions may be either ischaemic or nonischaemic. This division depends mainly on fluorescein angiographic and ophthalmoscopic criteria..$^{310-1+}$ We chose criteria (Table 1) that were based largely on the findings of Sinclair and Gragoudas ${ }^{14}$ but also took into account visual acuity, which has been stressed as an important parameter for the visual

Table 1 Criteria for non-ischaemic CRVO (at least two conditions have to be fulfilled)

(1) Fluorescein angiogram: time for maximal venous filling $\left(t_{m v f}\right)$ $<20$ s

(2) Capillary occlusion: area of $<1$ prism dioptre and/or $<10$ cotton-wool spots

(3) Visual acuity $>6 / 60$ 
Table 2 Entrance data of patients with non-ischaemic CRVO

\begin{tabular}{lcc}
\hline & IHD & Control \\
\hline Patients $(\mathrm{n})$ & 14 & 11 \\
Women $(\mathrm{n})$ & 6 & 7 \\
Age (years) & $64 \cdot 9($ SEM $2 \cdot 3)$ & $69 \cdot 4($ SEM 3.2) \\
Duration of occlusion (days) & $15 \cdot 0($ SEM 4.0) & $18 \cdot 0($ SEM 3.0) \\
Initial visual acuity $\geqslant 6 / 15(\mathrm{n})$ & 7 & 8 \\
Initial visual acuity $\leqslant 6 / 60(\mathrm{n})$ & 2 & 1 \\
\hline
\end{tabular}

outcome of patients with CRVO. ${ }^{2}$ Between August 1985 and December 1986 patients with non-ischaemic CRVO entered a randomised controlled study on IHD. After complete medical and ophthalmic examination they were randomly assigned by a lottery system to either control group (no treatment) or haemodilution group. However, it was not possible to treat these patients in a masked manner because the paleness of a haemodiluted patient cannot be hidden from the investigator.

Patients with systemic diseases (congestive heart failure despite treatment, renal insufficiency, and respiratory insufficiency of the pink puffer type, anaemia below $38 \%$ packed cell volume (PCV), thrombocytosis above $\left.450 \times 10^{4} / 1\right)$ insufficient clarity of media, pre-existing macular disease, and psychosocial problems that would not allow an outpatient haemodilution and long-time follow-up were excluded from the study (Table 2 ).

Complete ophthalmic examinations (visual acuity, slit-lamp examination of the anterior segment, gonioscopy, fundus biomicroscopy, applanation tonometry, visual fields (Goldmann), colour photography of the fundus) were done before haemodilution, in the sixth and twelvth week after the beginning of treatment, and thereafter every three months up to one year.

Visual acuity was determined fully refracted at $6 \mathrm{~m}$ by examiners who were not involved in the study. A change in visual acuity was considered to be present if the patient could read at least two steps more or less on the scale as shown in Figs. 1 and 2. It requires a reduction of the visual angle to nearly one-half in the upper end and to about one-quarter in the lower end of the scale. This fulfils at least the conditions for visual acuity change as demanded by the Diabetic Retinopathy Study Group. . $^{5}$

Fluorescein angiograms were done at the patient's first presentation and repeated after two and six weeks as well as after one year. Fluorescein $(10 \mathrm{mg} /$ $\mathrm{kg}$ ) was injected into the cubital vein within 3 seconds. The time from the appearance of the dye in the retinal arteries to the complete or maximal filling of the major temporal veins $\left(\mathrm{t}_{\mathrm{mvf}}\right)$ was used as indirect parameter for the flow velocity in retinal vessels. In addition the fluorescein angiograms were examined for areas of retinal capillary non-perfusion, completeness of the perifoveal arcade, leakage, and, in late stages, for intraretinal microvascular abnormalities and new vessel formation.

Haemodilution was induced as described previously." $300-500 \mathrm{ml}$ of whole blood was repeatedly taken from the cubital vein. After centrifugation the plasma was separated and reinfused. The lost volume of the blood cells was immediately replaced by $150-250 \mathrm{ml}$ of low molecular weight dextran (MW 40000). Possible anaphylactic reactions were prevented by intravenous injection of $20 \mathrm{ml}$ of small dextran molecules (MW 1000) as proposed by Hedin et al. ${ }^{16}$ During a one-week stay at hospital the PCV was reduced to $35-30 \%$ (in patients older than 75 years not below 35\%). During an additional fiveweek period dilution was repeated on an outpatient basis whenever the PCV exceeded $35 \%$.

The results of the statistical evaluation are expressed as mean values with standard error of the mean if not otherwise indicated. The significance of the difference between corresponding values was tested with Student's $t$ test. Visual acuity changes were tested by Fisher's exact test, based on the $\chi^{2}$ distribution $(2 \times 2$ table $)$.

\section{Results}

The randomised study had been planned for 40 patients, but was stopped for ethical reasons after a significant effect became obvious. So only 25 patients were enrolled in the randomised, controlled trial of the effect of IHD in non-ischaemic CRVO. Our classification was done during the first three days after the first presentation of the patient. Two of 14 eyes with non-ischaemic CRVO in haemodiluted patients converted to the ischaemic form (Table 1) in spite of haemodilution, whereas in control patients 4 of 11 eyes developed ischaemic CRVO, three of them within the first two months. These eyes underwent a panretinal photocoagulation, as has been reported elsewhere. ${ }^{\circ}$

The 25 patients were well matched on entry (Table 2) for sex, age, duration of occlusion, and initial visual acuity. All the patients could be examined after three months and only 24 patients after one year because one patient had meanwhile left the country. Whereas eight of 14 patients with IHD attained a better visual acuity after three months (Fig. 1), none of the 11 control patients had any visual improvement $(p<0.01)$. Deterioration occurred in two of the 14 haemodiluted and in four of the 11 control patients. After one year the rates of visual improvement were still the same in both groups and remained 


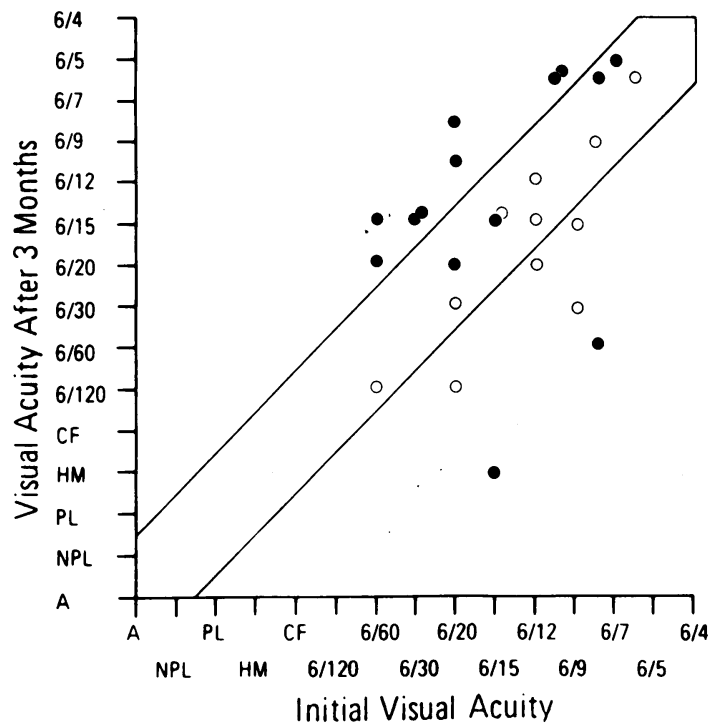

Fig. 1 Visual acuity before and three months after starting haemodilution in eyes with non-ischaemic CRVO (randomised study). Closed symbols stand for haemodiluted, open symbols for untreated eyes.

significantly different $(\mathrm{p}<0 \cdot 025$, Fig. 2). However, five of 11 control patients versus one of 13 haemodiluted patients showed a loss of more than two lines on the test chart.

The final visual acuity may be taken as another

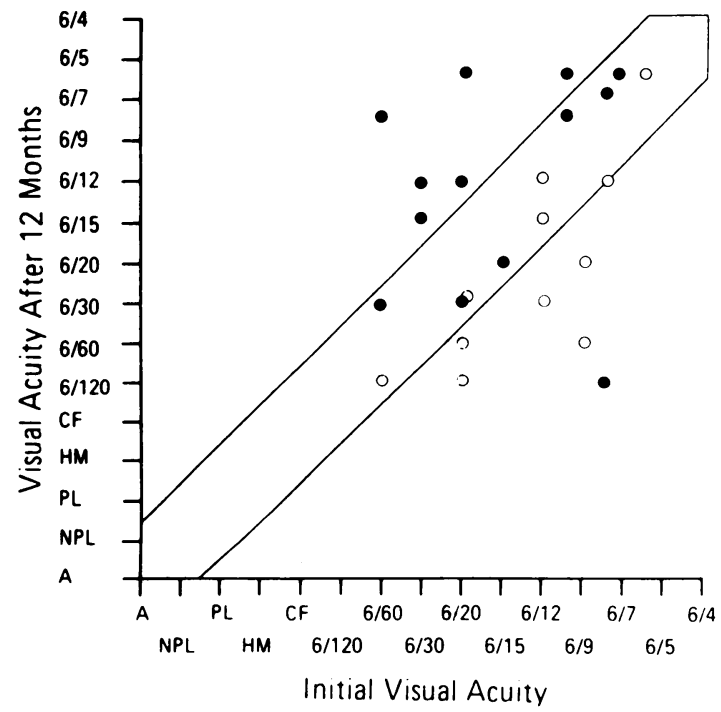

Fig. 2 Visual acuity before and 12 months after starting haemodilution in eyes with non-ischaemic CRVO (randomised study). Closed symbols stand for haemodiluted, open symbols for untreated eyes.

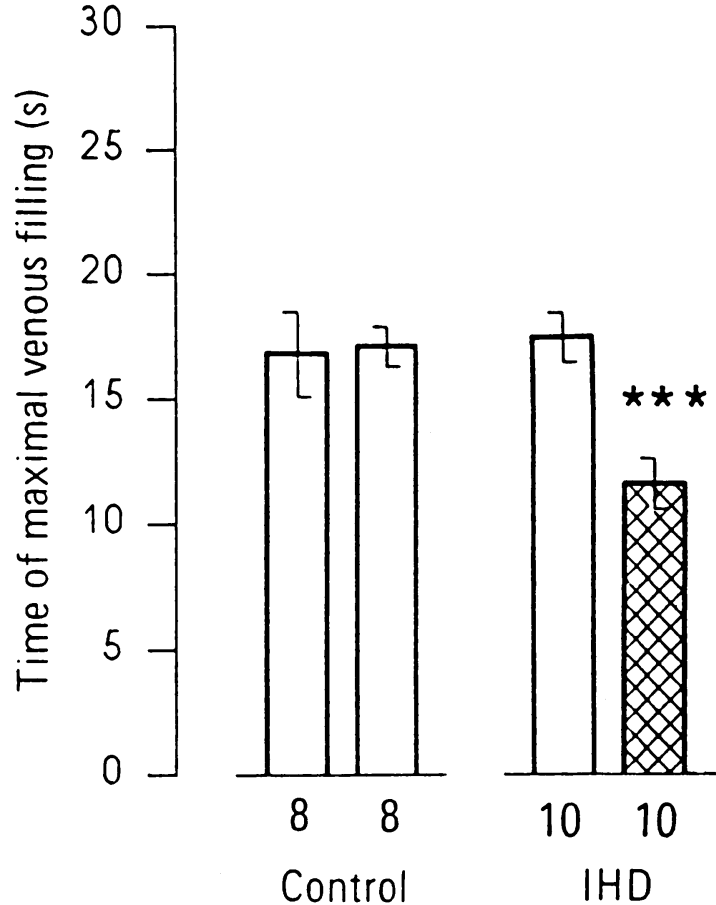

Fig. 3 Time of maximal venous filling (mean $\pm S E M$ ) in eyes with non-ischaemic $C R V O$ before and after isovolaemic haemodilution (hatched bars). Control patients (empty bars) received no treatment between the two angiograms. Number of eyes are given below the bars. $p<0.005(* * *)$.

indicator of the efficiency of IHD, especially if one takes into account the ability to read $(\geqslant 6 / 15)$. After three months the number of eyes with a visual acuity of $6 / 15$ or better had fallen from eight to six in control patients and increased from seven to 10 in haemodiluted patients. One year later only four eyes of the control group compared with nine of the haemodilution group reached a visual acuity of $6 / 15$ or more.

Only in 18 of 25 patients was it possible to get a series of two evaluable angiograms before and after IHD that could be compared with those of control patients without any treatment. The time of maximal venous filling $\left(t_{m v f}\right)$ is an important parameter for the severity of $\mathrm{CRVO}^{14}$ and may be used as an indicator for blood velocity in retinal veins. It normally takes 5-12 s from the first arterial appearance of the dye on the papilla until complete or maximal filling of the veins. ${ }^{17}$ This arteriovenous passage time was prolonged to $16 \cdot 8($ SEM 1.7) $s(n=8)$ and 17.4 (SEM 1.4) $s(n=10)$ in patients with non-ischaemic (CRVO) (Fig. 3). Two weeks later no change had occurred in control eyes $(17 \cdot 1($ SEM $0 \cdot 8) \mathrm{s}, \mathrm{n}=8)$, whereas the $\mathrm{t}_{\mathrm{muf}}$ was reduced to $11.4(\mathrm{SEM} 0.9) \mathrm{s}(\mathrm{n}=10)$ in haemodiluted patients $(\mathrm{p}<0 \cdot 0005)$. 


\section{Discussion}

The beneficial effect of isovolaemic haemodilution on the visual prognosis of patients with CRVO has been demonstrated before in two controlled studies. ${ }^{\circ}$ is The shortcomings of these studies were as follows: (1) the results were mainly based on subjective findings like visual acuity; (2) though both studies paid regard to the type of CRVO, the question whether IHD might also be a useful procedure in non-ischaemic CRVO was not solved. Our first controlled trial of IHD in CRVO showed an effect more often in ischaemic than in non-ischaemic CRVO.

We did not change our treatment scheme," originally proposed by Wiederholt et al. ${ }^{1 "}$ Problems of method and the applicability of IHD in the clinical routine are discussed in a separate paper..$^{2 n}$

One rationale for IHD is the finding of Ring et al and McGrath et al that patients with CRVO have higher whole blood and plasma viscosity than normal. These results have been corroborated" 1 " for patients with ischaemic CRVO. In our measurements of different haemorheological parameters we did not find rheological abnormalities in patients with ischaemic and non-ischaemic CRVO, but, as has been shown also by Heinen et al, 22 the fluidity of whole blood was markedly increased after IHD. ${ }^{23}$

Irrespective of a normal blood fluidity in patients with CRVO, local rheological factors should play a part in the compromised microcirculation of the retina. Independently of the primary event the blood flow decreases in venules and capillaries, thus leading to lower shear rates. It is well known that blood viscosity increases logarithmically with linear increase of PCV at a decrease of the shear rate. The increase of blood viscosity may be enhanced by haemoconcentration (plasma extravasation) and greater rigidity of erythrocytes (local acidosis). Thus a low blood velocity may strengthen a vicious circle and ultimately produce capillary lesions from ischaemia. To answer the question whether local rheological disturbances can be influenced by IHD we measured the time for maximal venous filling $\left(t_{m v f}\right)$, which reflects the blood velocity in retinal vessels. A decrease of whole blood viscosity shortened $t_{m v f}$. In control patients with nonischaemic CRVO no change of the passage time could be detected after two weeks. These findings suggest that the shortened $t_{\text {mvf }}$ is induced by a lower whole blood viscosity and hence demonstrates the local efficacy of IHD.

The visual prognosis of CRVO depends very much on the type of occlusion. ${ }^{3+6111123}$ Randomised studies $^{h}{ }^{1 x}$ on IHD have shown that an increase in visual acuity is more often seen in haemodiluted than in non-haemodiluted patients. This holds true also for patients with non-ischaemic CRVO, as has been shown by our randomised controlled trial (Figs. 1,2). If one considers all our haemodiluted patients, ${ }^{20}$ improvements are more often seen in eyes with ischaemic CRVO. Nevertheless, the prognosis of non-ischaemic CRVO is still better than that of its ischaemic counterpart. An important measure of a patient's visual acuity is the ability to read. In nonischaemic CRVO without haemodilution the rate of patients having a visual acuity of $6 / 15$ or better fell, indicating that this disease is not as benign as has been claimed by Hayreh. ${ }^{2+}$ This fall could finally be prevented by IHD in most cases.

In conclusion this study has shown that IHD may improve the visual prognosis in non-ischaemic as well as in ischaemic CRVO. The improvement is probably induced by a decrease in whole blood viscosity, which leads to a higher blood velocity in areas of compromised retinal microcirculation. The effect of isovolaemic haemodilution only partly influences the visual prognosis of CRVO because it does not eliminate the cause of the obstruction.

This study was supported by the Deutsche Forschungsgemeinschaft (grant Ga 225/6-1).

\section{References}

1 Michel J von. Die spontane Thrombose der Vena centralis des Opticus. Gracfes Arch Clin Exp Ophthalmol 1978: 24: 37-44.

2 Quinlan P. Chauclary A. Elman MJ. Enger C. The natural history of central retinal vein occlusion. Inve'st Ophthalmol Vis Sci 1987; 28 (suppl): 319.

3 Laatikainen LL. Kohner EM, Khoury D, Blach RK. Panretinal photocoagulation in central retinal vein occlusion: a randomised controlled clinical study. Br J Ophthalmol 1977: 61: 741-53.

4 May DR, Klein MR. Peyman GA, Raichaud M. Xenon are panretinal photocoagulation for central retinal vein occlusion: a randomised prospective study. Br J Ophthalmol 1979; 63: 72534.

5 Magargal LE, Brown GC, Augsburger JJ, Donoso LA. Efficiency of panretinal photocoagulation in preventing neovascular glaucoma following ischemic central retinal vein obstruction. Ophthalmology 1982; 89: 78()-4.

6 Hansen LL, Danisevskis P, Arntz HR, Hövener G, Wiederholt M. A randomised prospective study on treatment of central retinal vein occlusion by isovolaemic haemodilution and photocoagulation. BrJ Ophthalmol 1985: 69: 108-16.

7 Ring CP. Pearson TC, Sanders MD. Wetherley-Mein G. Viscosity and retinal vein thrombosis. $\mathrm{BrJO}$ (O)hthalmol 1976; 60: 397-410.

8 McGrath MA, Wechsler F, Hunyor ABL, Penny R. Systemic factors contributory to retinal vein occlusion. Arch Intern Med 1978: 138: 216-20.

9 Trope GE, Lowe GDO. McArdle BM, et al. Abnormal hlood viscosity and haemostasis in longstanding retinal vein occlusion. Br J Ophthalmol 1983; 67: 137-42.

10 Laatikainen LL. Kohner EM. Fluorescein angiography and its prognostic significance in central retinal vein occlusion. $\mathrm{Br} J$ Ophthalmol 1976; 60: 411-5.

11 Hayreh SS. So-called, central retinal vein occlusion. I. Pathogenesis, terminology, clinical features. Ophthalmologica 1976; 172: $1-13$. 
12 Hayreh SS. Classification of central retinal vein occlusion. Ophthalmology 1983; 90: 458-74.

13 Welch JC, Augsburger JJ. Assessment of angiographic retinal capillary nonperfusion in central retinal vein occlusion. Am J Ophthalmol 1987: 103: 761-6.

14 Sinclair SH. Gragoudas ES. Prognosis for rubeosis iridis following central retinal vein occlusion. Br J Ophthalmol 1979: 63: $73.5-43$.

15 Diabetic Retinopathy Study Research Group: Report No. 6: Design, methods, baseline results. Invest Ophthalmol Vis Sci 1981: 21: 1-209.

16 Hedin H, Richter W, Ring J. Dextran-induced anaphylactoid reactions in man. Role of dextran-reactive antibodies. Int Arch Allergy Appl Immunol 1976; 52: 145-9.

17 Richard G, Darrelmann OG, Kreissig I, Schubring G, Weber J. Videoangiographische Unterteilung der Netzhautkreislaufzeit. Ihre Bedeutung für die Diagnostik von Durchblutungsstörungen der Netzhaut. Forlschr Ophthalmol 1984: 81: 592-5.

18 Brunner R. Heinen A, Konen W, Hossmann V, Gaethgens P. Therapie retinaler Durchblutungsstörungen durch Beeinflussung der Blutviskosität eine randomisierte Doppelblindstudie. Fortschr Ophthalmol 1984:81: 440-8.

19 Wiederholt M. Leonhardt H, Schmid-Schönbein H, Hager H. Die Behandlung von Zentralvenenverschlüssen und Zentra- larterienverschlüssen mit isovolämischer Hämodilution. Klin Monatshl Augenheilk 1980; 177: 157-64.

20) Hansen LL, Wiek J, Müller-Stolzenburg N, Schade M, Wiederholt $M$. The effect and compatibility of isovolaemic haemodilution in the treatment of ischaemic and non-ischaemic central retinal vein occlusion. Ophthalmologica (In press).

21 Peduzzi M, Debbia A. Guerrierri F, Bolzani R. Abnormal blood viscosity and filterability in retinal vein occlusion. Clin Hemorrheol 1984; 4: 555-61.

22 Heinen A. Brunner R, Hossmann V. Konen W. Roll K. Warer T. Different types of therapy having hemorheological effects in patients with impairment of blood supply to the retina (randomized double-blind study). Clin Hemorheol 1986; 6: 61-79.

23 Hansen LL, Wiek J, Wiederholt M. Isovolaemic haemodilution in ischaemic and non-ischaemic central retinal vein occlusion. In: Ben Ezra D, Ryan SJ, Glaser BM, Murphy RP, eds. Ocular circulation and neovascularisation. Doc Ophthalmol Proc Series 1987: 50: 23-9.

24 Hayreh SS. So-called, central retinal vein occlusion. II. Venous stasis retinopathy. Ophthalmologica 1976: 172: 14-37.

Accepted for publication 14 June 1989. 